\title{
Derivation of physically motivated wind speed scales
}

\author{
Nikolai Dotzek* \\ Deutsches Zentrum für Luft- und Raumfahrt (DLR), Institut für Physik der Atmosphäre, Oberpfaffenhofen, 82234 Wessling, Germany \\ European Severe Storms Laboratory (ESSL), Münchner Str. 20, 82234 Wessling, Germany
}

\section{A R T I C L E I N F O}

\section{Article history:}

Received 2 December 2007

Received in revised form 27 September 2008

Accepted 14 October 2008

\section{Keywords:}

Wind speed scale

E-scale

Fujita scale

EF-scale

Calibration

\begin{abstract}
A B S T R A C T
A class of new wind speed scales is proposed in which the relevant scaling factors are derived from physical quantities like mass flux density, energy density (pressure), or energy flux density. Hence, they are called Energy- or E-scales, and can be applied to wind speeds of any intensity. It is shown that the Mach scale is a special case of an E-scale. Aside from its foundation in physical quantities which allow for a calibration of the scales, the E-scale concept can help to overcome the present plethora of scales for winds in the range from gale to hurricane intensity. A procedure to convert existing data based on the Fujita-scale or other scales (Saffir-Simpson, TORRO, Beaufort) to their corresponding E-scales is outlined.

Even for the large US tornado record, the workload of conversion in case of an adoption of the E-scale would in principle remain manageable (if the necessary metadata to do so were available), as primarily the F5 events would have to be re-rated. Compared to damage scales like the "Enhanced Fujita" or EF-scale concept recently implemented in the USA, the E-scales are based on first principles. They can consistently be applied all over the world for the purpose of climatological homogeneity.

To account for international variations in building characteristics, one should not adapt wind speed scale thresholds to certain national building characteristics. Instead, one worldwide applicable wind speed scale based on physical principles should rather be complemented by nationally-adapted damage descriptions. The E-scale concept can provide the basis for such a standardised wind speed scale.
\end{abstract}

(c) 2008 Elsevier B.V. All rights reserved.

\section{Introduction}

Development of wind speed scales has long been a subject of research, and Fujita (1981) has provided a review of the field focusing on those scales which were designed to describe the most intense wind phenomena on earth: Tornadoes, downbursts, and tropical cyclones. Inherently, the task of devising scales for high wind events can be tackled from two sides:

(i) wind speed-based, and

(ii) damage-based.

\footnotetext{
* Tel.: +49 815328 1845; fax: +498153281841.

E-mail address: nikolai.dotzek@dlr.de.

URL: http://essl.org/people/dotzek/.
}

The former approach is usually taken in the atmospheric sciences, while the latter reflects more the standpoint of wind engineering. However, the conceptual difference and partial incompatibility of both approaches has led to considerable controversy and confusion over recent decades, primarily because even wind speed-based scales must usually rely on post-event damage surveys, due to the scarcity of in situ wind measurements, at least in tornadoes and downbursts.

The difference between approaches (i) and (ii) above can be substantial, as wind speed-based scales are in general concerned about the maximum winds that can physically occur for a given wind phenomenon, and in particular about what the maximum (local) intensity (wind speed) for a given event was. Damage-based scales, however, focus on determining the minimum wind speed necessary to cause the observed damage to individual man-made structures or vegetation. Secondarily, a likely upper bound of wind speeds 
can be estimated in those cases in which undamaged structures remain, for which apparently their critical damaging wind speed level had not been attained in the storm.

Three wind speed scales are frequently used in meteorology, wind engineering and related sciences: the Beaufort (B), Fujita (F), and TORRO (T) scales. The relationship between velocity $v$ and the scale value $\mathrm{X}$ in these various scales can be described as

$v(X)=v_{*}\left(X-X_{0}\right)^{3 / 2}$,

with $v *$ being a scaling velocity and $\mathrm{X}_{0}$ denoting an offset to account for the fact that wind damage may only occur above a certain critical wind speed.

Eq. (1) illustrates that scales considering any moderate wind speed (like the B-scale) are characterized by an offset $\mathrm{X}_{0}=0$, whereas high wind speed scales like F- or T-scale have $\mathrm{X}_{0}<0$. In the latter case, the scales have one or more subcritical classes below the critical threshold velocity $v(0)$, usually related to the emergence of a certain level of wind damage. The F- and T-scales, for instance, put the critical threshold near $18 \mathrm{~m} \mathrm{~s}^{-1}$, consistent with worldwide insurance practice in handling wind damage claims.

Eq. (1) may also be used for an approximation of the SaffirSimpson (S) scale mainly applied to hurricane winds over the Atlantic basin. The F, T, and S-scales classify the physically possible velocity range for tornadoes, downbursts, and tropical cyclones. This makes them applicable worldwide in a consistent way - an important point in climatological analysis. Yet, the question if the exponent 3/2 in Eq. (1) is the best possible choice was often raised, and this paper aims at answering it.

To include the variation in building strength in different regions of the world, local descriptions of typical damage for each scale class are needed. Fujita $(1971,1981,1992)$ and NOAA-NWS (2003) have provided this with growing detail for the USA. Dotzek et al. (2000) and Hubrig (2004) present a damage description for central Europe ${ }^{1}$ over $\mathrm{F}$ - and T-scale which was developed with input by Munich Reinsurance Group and also describes vegetation damage, traditionally taken into account in European wind damage ratings.

In contrast to the $\mathrm{F}$ - or T-scales, the recently proposed "Enhanced Fujita" or EF-scale (McDonald, 2002; McDonald et al., 2003, 2004; WSEC, 2004) is a purely damage-based scale. It classifies the damage observed for typical structures in the USA and then assigns, based upon an expert elicitation, velocities claimed sufficient to explain the degree of damage. Above $89.4 \mathrm{~m} \mathrm{~s}^{-1}$, i. e. $322 \mathrm{~km} \mathrm{~h}^{-1}$ (200 miles $\left.\mathrm{h}^{-1}\right)$, no further discrimination is made by the EF-scale. Besides, the EF-scale damage description is local (adapted to the average USA situation) and yet to be devised descriptions for other regions worldwide (or even sub-regions of the USA) might also require alteration of the elicited wind speed thresholds. Thus, the EF-scale is not readily applicable internationally. Any resulting variations in threshold values from country to country could severely affect the climatological consistency

\footnotetext{
1 The description is available online in German at www.tordach.org/pdf/ FT_scales.pdf. An updated English version is currently being prepared and will appear on the ESSL website under www.essl.org/research/scales/.
}

of worldwide tornado records. The EF-scale was implemented in the USA by NOAA on 1 February 2007, despite the ongoing and unresolved discussion in the atmospheric sciences if the EF-scale is indeed an enhancement of the F-scale (cf. Doswell, 2006; Potter, 2007; Doswell et al., 2009-this issue).

This paper aims to develop velocity scaling laws which avoid the flaws of the scales identified in Section 2 and also allow for a calibration to findings from statistical modelling, wind engineering, damage analyses or mobile Doppler radar measurements. After an overview of the presently existing scales in Section 2, the E-scales resulting from these requirements are developed and related to the physical variables mass flux density, energy density and energy flux density in Section 3. Conversion of, for instance, existing Fujita-scale data to the E-scale is an issue of great practical importance and also exemplified there. Sections 4 and 5 present discussion and conclusions.

\section{Characteristics of the existing scales}

The B-scale results from an empirical fit of mean wind speeds (10 min average) at about $10 \mathrm{~m}$ height to Beaufort's original and later descriptions of the wind force or wind effects, respectively. Müller (1979) reviewed the following formula, among others, based on WMO tables (WMO, 1975):

$\bar{v}(B)=0.835 \mathrm{~ms}^{-1} B^{3 / 2}$.

Note that the B-scale is defined such that integer scale values are centred in their respective $B$ class, and do not give the velocity thresholds between these classes. A vivid illustration of this property is that the B0 class centred at $v=0 \mathrm{~m} \mathrm{~s}^{-1}$ would formally have a lower threshold at negative wind speeds. Hence, the B-scale is staggered by $1 / 2$ class width compared to a formalism indicating the lower thresholds of scale classes for integer scale values.

The T-scale describes peak winds, yet was designed as a formal extension of the B-scale (Meaden, 1976). Its $v(\mathrm{~T})$ relation reads

$\bar{v}(T)=2.362 \mathrm{~ms}^{-1}(T+4)^{3 / 2}$,

where $v_{*}=2.362 \mathrm{~m} \mathrm{~s}^{-1}$ follows from $\bar{v}(\mathrm{~T}=0)=\bar{v}(\mathrm{~B}=8)$. Note that while the width of one T-scale class exactly corresponds to that of two B-scale classes, integer scale values $\mathrm{T}$ are no longer centred in their respective $\mathrm{T}$ class. Instead, T-scale class thresholds are staggered by $1 / 4$ class width compared to the central class value, that is, the T0 class range is $[\mathrm{T}=-0.25, \mathrm{~T}=0.75]$ such that $\bar{v}(\mathrm{~T}=0)=\bar{v}(\mathrm{~B}=8)$, cf. Table 1 . This complicated property may be one explanation why the T-scale has not gained widespread acceptance.

The following scales all indicate the thresholds between scale classes for integer scale values and are in this sense better-behaved. The S-scale developed in 1971 (cf. Simpson, 1974) for measuring hurricane winds has similar velocity increments like the T-scale, but refers to $1 \mathrm{~min}$ wind speed averages and attains positive scale values only at higher wind speed than the T-scale. Owing to its counter-intuitive nonmonotonicity in velocity increments (which is the likely reason that no formal $v(\mathrm{~S})$ relation has apparently been 
Table 1

Homogenized wind speeds and increments of the T- and F-scales following Dotzek et al. (2000, 2003).

\begin{tabular}{|c|c|c|c|c|c|c|c|c|}
\hline \multirow{3}{*}{$\frac{\text { Fujita }}{\text { TORRO }}$} & \multicolumn{4}{|c|}{ Sub-critical } & \multicolumn{4}{|l|}{ Weak } \\
\hline & \multicolumn{2}{|l|}{$\mathrm{F}-2$} & \multicolumn{2}{|l|}{$\mathrm{F}-1$} & \multicolumn{2}{|l|}{$\overline{\mathrm{F} 0}$} & \multicolumn{2}{|l|}{$\mathrm{F} 1$} \\
\hline & $\mathrm{T}-4$ & $\mathrm{~T}-3$ & $\mathrm{~T}-2$ & $\mathrm{~T}-1$ & T0 & $\mathrm{T} 1$ & $\mathrm{~T} 2$ & T3 \\
\hline Beaufort & B0, B1 & B2, B3 & B4, B5 & B6, B7 & B8, B9 & B10, B11 & B12, B13 & B14, B15 \\
\hline$v$ in $\mathrm{m} \mathrm{s}^{-1}$ & $0-3$ & $3-7$ & $7-12$ & $12-18$ & $18-25$ & $25-33$ & $33-42$ & $42-51$ \\
\hline$v$ in $\mathrm{km} \mathrm{h}^{-1}$ & $0-11$ & $11-25$ & $25-43$ & $43-65$ & $65-90$ & $90-119$ & $119-151$ & $151-184$ \\
\hline$\Delta v$ in $\mathrm{ms}^{-1}$ & 3 & 4 & 5 & 6 & 7 & 8 & 9 & 9 \\
\hline$L-$ in $\%$ & 0 & 0 & 0 & 0.01 & 0.05 & 0.1 & 0.25 & 0.8 \\
\hline \multirow[t]{3}{*}{$L+$ in $\%$} & 0 & 0 & 0 & 0 & 0.01 & 0.05 & 0.1 & 0.25 \\
\hline & \multicolumn{8}{|c|}{ Significant } \\
\hline & \multicolumn{4}{|l|}{ Strong } & \multicolumn{4}{|l|}{ Violent } \\
\hline Fujita & \multicolumn{2}{|l|}{$\overline{\mathrm{F} 2}$} & \multicolumn{2}{|l|}{ F3 } & \multicolumn{2}{|l|}{$\overline{\mathrm{F} 4}$} & \multicolumn{2}{|l|}{ F5 } \\
\hline TORRO & $\mathrm{T} 4$ & T5 & $\overline{\mathrm{T} 6}$ & $\mathrm{~T} 7$ & $\mathrm{~T} 8$ & T9 & T10 & T11 \\
\hline Beaufort & B16, B17 & B18, B19 & B20, B21 & B22, B23 & B24, B25 & B26, B27 & B28, B29 & B30, B31 \\
\hline$v$ in $\mathrm{m} \mathrm{s}^{-1}$ & $51-61$ & $61-71$ & $71-82$ & $82-93$ & $93-105$ & $105-117$ & $117-130$ & $130-143$ \\
\hline$v$ in $\mathrm{km} \mathrm{h}^{-1}$ & $184-220$ & $220-256$ & $256-295$ & $295-335$ & $335-378$ & $378-421$ & $421-468$ & $468-515$ \\
\hline$\Delta v$ in $\mathrm{m} \mathrm{s}^{-1}$ & 10 & 10 & 11 & 11 & 12 & 12 & 13 & 13 \\
\hline$L-$ in $\%$ & 3 & 10 & 30 & 90 & 100 & 100 & 100 & 100 \\
\hline$L+$ in $\%$ & 0.8 & 3 & 10 & 30 & 60 & 80 & 90 & 95 \\
\hline
\end{tabular}

For comparison, the coarse verbal K-scaling from the analysis by Kelly et al. (1978) and the corresponding steps on the Beaufort scale are given, also extending beyond the usual upper limits of B12 or B18. $L-$ and $L+$ denote loss ratios in Central Europe for light-structure and solid buildings, respectively.

published before), the S-scale can only be approximated with the expression

$v(S) \approx 1.825 \mathrm{~ms}^{-1}(S+6)^{3 / 2}$.

Possible ways to enhance this traditional S-scale have already been discussed by Kantha (2006, 2008), Powell and Reinhold (2007a,b, 2008a,b) and Simpson and Saffir (2007) as well as Hsu and Blanchard (2008).

The F-scale (Fujita, 1971; Fujita and Pearson, 1973; Fujita, 1981) for peak winds ${ }^{2}$ in hurricanes and tornadoes was also related to the B-scale, but gives scale class thresholds, not central values. From the conditions $v(\mathrm{~F}=0)=v(\mathrm{~B}=7.5)$, that is, lower bound of $\mathrm{B} 8$ class, and $v(\mathrm{~F}=1)=v(\mathrm{~B}=11.5)$, the lower bound of B12 class, and finally $v(\mathrm{~F}=12)=\mathrm{M} 1$ (Mach 1 , speed of sound), Fujita arrived at

$v(F)=6.302 \mathrm{~ms}^{-1}(F+2)^{3 / 2}$.

Table 1 gives a schematic overview of the F- and T-, B-scales. For this purpose, the slightly differing velocity thresholds of the three scales had been homogenized by Dotzek et al. (2000, 2003) for clarity and simplicity - a procedure which has recently been advocated by the inventor of the T-scale as well (Meaden et al., 2007).

Aside from small velocity differences between corresponding F- and T-scale thresholds, the more fundamental difference between them has to be stressed again: T-scale values from Eq. (3), similar to B-scale values from Eq. (2), yield some average velocity $\bar{v}$ (but not the arithmetic mean $<v>$, cf. the Appendix) of the respective T- or B-scale class, and not the lower threshold of this class. The latter is true for the F-scale, however. For instance, $\mathrm{F}=0$, often abbreviated as F0, is equivalent to $v=17.8 \mathrm{~m} \mathrm{~s}^{-1}$, the lower bound of the F0 class. However, $\mathrm{T} 0=\mathrm{B} 8$ being equivalent

\footnotetext{
2 Or rather the "fastest quarter-mile wind", that is, the maximum gust speed $v_{g}$ fulfilling $v_{g} \Delta t_{g}=402.25 \mathrm{~m}$, in which $\Delta t_{\mathrm{g}}$ denotes the gust duration.
}

to $\bar{v}=18.9 \mathrm{~m} \mathrm{~s}^{-1}$ is the central value of the B8 class, as well as the lower quarter value of the T0 class, and thus the T0 class minimum value lies at T- 0.25 , corresponding to $\bar{v}=17.2 \mathrm{~m} \mathrm{~s}^{-1}$.

So the central class value $\bar{v}$ concept of the B-scale, which may appear attractive at first glance, reveals its shortcomings and complications only under closer inspection, especially when handed down to the T-scale design. The B-scale is also not very practical for extreme and damaging wind speeds, which are better measured or scaled by decision on whether the winds exceed certain thresholds. Besides, the central class value concept of the $\mathrm{B}$ - and T-scales leads to the unwanted fact that the actual scale class boundaries do not obey their own scaling relation $\bar{v}(\mathrm{X})$, neither in the prefactor $v_{*}$ nor in the exponent $3 / 2$. Finally, the leftward curvature of the nonlinear $\bar{v}(\mathrm{X})$ relations has the disadvantage that the average wind speed $\langle v>$ of e. g. a B-scale class is always larger than the central $\bar{v}(\mathrm{~B})$ value (see the Appendix, and cf. Müller, 1979).

In addition, there are other flaws not only with the T-, Band S-, but also the F-scale:

- The exponent $3 / 2$ bears no physical significance; i. e. it is not obviously related to any relevant physical quantity;

- The offsets $\mathrm{X}_{0}=-2$ (F-scale, Eq. (5)), $\mathrm{X}_{0}=-4$ (T-scale, Eq. (3)), and $X_{0}=-6$ (S-scale, Eq. (4)) inherently imply two, four or even six scale classes in the sub-critical wind speed range and thus offer too much detail there;

- The scales' steps are not uniform, neither in velocity (or mass flux density), kinetic energy density (or pressure), nor in energy flux density. For the original S-scale, they are not even monotonic;

- For gale- to hurricane-force winds, a plethora of four different wind speed scales is available, resulting in a lack of coherence when worldwide wind speed data from this range are compared on the basis of scale ratings.

Most of these flaws can be eliminated, and a procedure for calibration be added, by the development of the E-scale in the next section. 


\section{The E-scale}

The E-scale derivation will start from the most widely accepted high wind speed scale, the F-scale following Eq. (5), and then proceed via the related Kelly et al. (1978) scaling, here designated as the K-scale. The velocity ranges and number of scale classes of both these well-accepted scales will serve as an exemplary frame of reference for the development of the new scales. Note that the F- and K-scales, as well as the $\mathrm{S}$ - and the new E-scales are defined to give the class boundaries in wind speed, that is, integer scale values denote the threshold from a lower scale class to the next higher one. Formally, using again X as in Eq. (1) as a general variable for any of the above scales, this is equivalent to

$X$ value : $\quad X=n \Leftrightarrow X n ; \quad v(X n)=$ lower bound of class $X n,(6 a)$

X class : $\quad X=n \Leftrightarrow X n \quad \Rightarrow v(X n) \leq v<v(X n+1)$.

\subsection{From the F-scale to the Kelly et al. scaling (K-scale)}

One flaw of e.g. the current F- and T-scales is that they distinguish more than one sub-critical class (so, $\mathrm{X}_{0}<-1$ ). Ideally, there should be only one such class. It will be demonstrated later on that this cannot be fulfilled in all cases, but that at least the E-scales always reduce the number of sub-critical classes compared to present scales.

So, the first step is to set $\mathrm{X}_{0}=-1$ as default for any new high wind speed scale in order to avoid unwanted detail with subcritical winds (recall that wind speed scales considering any wind speed relevant, like the $\mathrm{B}$-scale, have $\mathrm{X}_{0}=0$ ). This has interesting implications for the relation of the F-scale to the coarser scaling apparently first described in the scientific literature by Kelly et al. (1978). As Table 1 shows, they grouped two F-scale classes together, yet devised only a verbal description for their scale: [F0, F1] events were termed "weak", [F2, F3] "strong", and [F4, F5] "violent". The one remaining group, [F-2, F-1], was named "sub-critical” by Dotzek et al. (2003).

This verbal K-scale can readily be quantified using the above requirement $\mathrm{X}_{0}=-1$ :

$v(K)=v_{*}(K+1)^{3 / 2}$, where $v_{*}=v(F=0)=17.825 \mathrm{~ms}^{-1}$.

Eq. (7) exactly reproduces the F-scale boundaries F-2, F0, F2, $\mathrm{F} 4$, F6 for the $\mathrm{K}$-scale values $\mathrm{K}-1, \mathrm{~K} 0, \mathrm{~K} 1, \mathrm{~K} 2$, and $\mathrm{K} 3$. This is illustrated in Fig. 1, revealing that Eqs. (5) and (7) describe the same non-dimensional curve $v / v *$.

Yet, aside from being too coarse, for instance, for statistical modelling of tornado intensity distributions, the K-scale still shows the empirical and arbitrary exponent $3 / 2$, the scaling is not linked to physical quantities, and the width of scale classes strongly grows with increasing $\mathrm{K}$. The latter is a fact sometimes criticized already in the F-scale context by insurers and wind engineers. In light of the next subsection, this growth can be quantified by rewriting Eq. (7) as:

$v(K)=v_{*}(K+1)^{1 / 2}(K+1)=v_{*}^{\prime}(K+1)$, where $v_{*}^{\prime}=v_{*}(K+1)^{1 / 2}$.

Apparently, the effective $v_{*}^{\prime}$ itself is a monotonically increasing function of scale parameter K. The F-, T-, S-, and B-scales show analogous behaviour.

\subsection{Derivation of the E-scale}

To further avoid the flaws identified at the end of Section 2, any formulation of new scales should be based on, or at least linked to, physical observables, like the maximum horizontal wind speed $v$ (or momentum density), maximum values of kinetic energy $\left(\propto v^{2}\right)$ or energy-flux density $\left(\propto v^{3}\right)$. Note that as only the magnitude of the wind is relevant here, we can replace the vector quantities $\boldsymbol{v}$ and $\boldsymbol{v}^{\mathbf{3}}$ by their absolute values without loss of generality. These three observables bear more physical relevance than any formal scale variable $\mathrm{X}$ and, depending on structural characteristics, $v^{2}$ or $v^{3}$ are directly related to wind load and damage (Betz, 1926; Emanuel, 2005, 2007; Webster et al., 2005):

$v=\frac{M}{\rho}, \quad \frac{2 E_{k i n}}{\rho}=v^{2}=\frac{2 \Delta p_{s}}{\rho}, \quad v^{3}=\frac{2 P_{k i n}}{\rho}$.

Eq. (9) shows that $v$ is coupled to the specific values of mass flux $M$, kinetic energy $E_{k i n}$, stagnation pressure difference $\Delta p_{s}$, and energy flux density $P_{k i n}$, while $\rho$ denotes air density. In effect, the physical quantities useful for wind speed scales and possible calibration to e. g. wind engineering or Doppler radar results are:

$M=\rho v, \quad[M]=\mathrm{kg} \mathrm{m}^{-2} \mathrm{~s}^{-1}, \quad$ mass flux density,

$E=\rho / 2 v^{2},[E]=\mathrm{J} \mathrm{m}^{-3}=P a$, energy density $=$ pressure, $(10 \mathrm{~b})$

$P=\rho / 2 v^{3}, \quad[P]=\mathrm{W} \mathrm{m}^{-2}$, energy flux density.

\subsubsection{Linear scaling}

The first and seemingly natural approach is to apply a linear, uniform scaling in each of the quantities $M, E, P$ and to

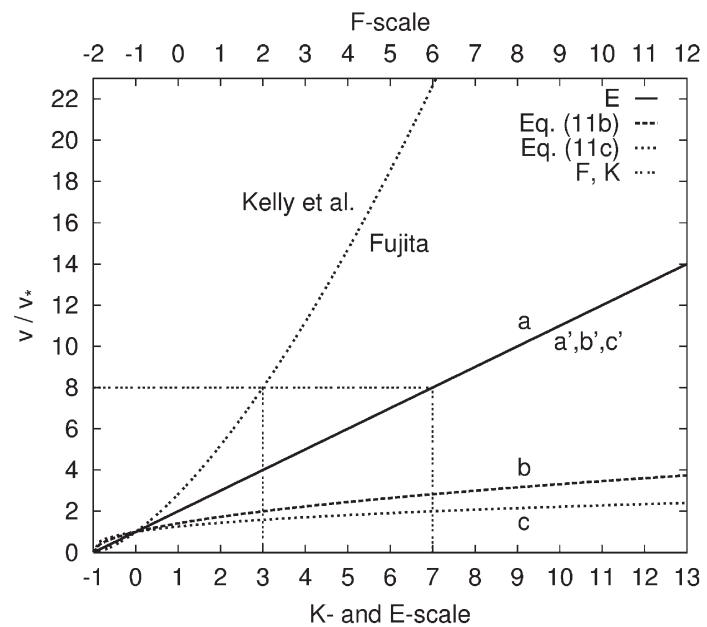

Fig. 1. Non-dimensional velocity relations as a function of different wind speed scales. The upper curve represents both Fujita's F-scale definition and the present K-scale alluded to by Kelly et al. (1978). Curves (b) and (c) represent scaling laws from Eqs. (11b), (11c) with constant steps in energy density (pressure) and energy flux density, respectively. The linear curves (a), $\left(a^{\prime}\right)$ have constant steps in mass flux density, and are congruent to $\left(b^{\prime}\right)$ and $\left(c^{\prime}\right)$, also in the final form of the E-scale. The lower left dotted rectangles mark the relevant region of application for the E- and K-scales. 
relate this to corresponding velocity relations $v(\mathrm{X})$. However, this intuitive approach will prove to be impracticable.

$m_{*}(X+1)=\rho v \Rightarrow v(X)=v_{*}(X+1), v_{*}=\rho^{-1} m_{*}, \quad(11 \mathrm{a})$
$\varepsilon_{*}(X+1)=\rho / 2 v^{2} \Rightarrow v(X)=v_{*}(X+1)^{1 / 2}, v_{*}=\left[2 \rho^{-1} \varepsilon_{*}\right]^{1 / 2}$,

$\boldsymbol{\rho}_{*}(X+1)=\rho / 2 v^{3} \Rightarrow v(X)=v_{*}(X+1)^{1 / 3}, v_{*}=\left[2 \rho^{-1} \boldsymbol{\rho}_{*}\right]^{1 / 3}$.

These relations are shown in Fig. 1 and denoted (a), (b), (c), respectively. The scale increments $\boldsymbol{m}_{*}, \varepsilon_{*}$, and $\boldsymbol{p}_{*}$ are the quantities which can be used to calibrate the scales which will necessarily be in the Form $v(\mathrm{X})$.

Unfortunately, Eqs. (11b)-(11c) and Fig. 1 reveal that uniform linear scaling in quantities $E$ and $P$ does lead to nonlinear increments in $v$, and only for the mass flux density $M$ are both scalings in $M$ and $v$ linear. As with the K-scale from Eqs. (7) and (8), the effective $v_{*}^{\prime}$ in Eqs. (11b), (11c) itself is a monotonic, but now decreasing function of scale parameter $\mathrm{X}$ :

$v(X)=v_{*}(X+1)^{-1 / 2}(X+1)=v_{*}^{\prime}(X+1)$, where $v_{*}^{\prime}=v_{*}(X+1)^{-1 / 2}$

$v(X)=v_{*}(X+1)^{-2 / 3}(X+1)=v_{*}^{\prime}(X+1)$, where $v_{*}^{\prime}=v_{*}(X+1)^{-2 / 3}$

Only Eq. (11a) displays a genuinely constant value of $v *$ compared to the $v_{*}^{\prime}$ functions in Eqs. (12a), (12b). Fig. 1 further reveals the major practical disadvantage of linear scaling in non-linear quantities like in Eqs. (11b), (11c): The exponents 1/ 2 and $1 / 3$ lead to very slowly increasing functions $v(\mathrm{X})$. Hence, it is almost impossible to map wind speeds of about $143 \mathrm{~m} \mathrm{~s}^{-1}$ (the upper threshold of the F5 range) like those measured in the most violent tornadoes (cf. Monastersky, 1999; Potter, 2007) with a limited number of scale classes, unless an unreasonably large value for $v *$ is chosen (which would, however, make the scale also very coarse again).

\subsubsection{Non-linear scaling}

To circumvent these difficulties with the linear scaling in $E$ and $P$ from Eqs. (11b), (11c), it is necessary to introduce a non-linear scaling in which the effective $v_{*}^{\prime} \equiv v_{*}=$ const. Consequently, I finally propose the following generic type of scaling:

$X_{*}\left(X-X_{0}\right)^{n}=a_{x} v^{n} \Rightarrow v(X)=v_{*}\left(X-X_{0}\right), v_{*}=\left[a_{x}^{-1} X_{*}\right]^{1 / n}$.

Herein the scaling quantity $X_{*}$, the prefactor $a_{x}$ and the exponent $n$ depend on the physical observables $(M, E, P)$ in which the non-linear scaling is performed. Application of this scaling leads to modified forms of Eqs. (11a)-(11c), requiring again $\mathrm{X}_{0}=-1$ :

$m_{*}(X+1)=\rho v \Rightarrow v(X)=v_{*}(X+1), v_{*}=\rho^{-1}, m_{*}$

$\varepsilon_{*}(X+1)^{2}=\rho / 2 v^{2} \Rightarrow v(X)=v_{*}(X+1), v_{*}=\left[2 \rho^{-1} \varepsilon_{*}\right]^{1 / 2}$,

$\mathcal{P}_{*}(X+1)^{3}=\rho / 2 v^{3} \Rightarrow v(X)=v_{*}(X+1), \quad v_{*}=\left[2 \rho^{-1} \mathcal{P}_{*}\right]^{1 / 3}$.
As the scaling velocities are related to energy via $\varepsilon_{*}$ or $\boldsymbol{D}_{*}$, the new scale from Eq. (13) is henceforth termed the "Energyscale" or E-scale.

For this E-scaling, depicted by the linear $v(\mathrm{X})$ function and denoted by $\left(\mathrm{a}^{\prime}\right),\left(\mathrm{b}^{\prime}\right),\left(\mathrm{c}^{\prime}\right)$ in Fig. 1 all values $v *$ in Eqs. (14a)(14c) are constant (but not necessarily the same). This means that for externally specified critical values of $m_{*}, \varepsilon_{*}$, or $p_{*}$, the individual scaling velocity $v_{*}$ can be computed (calibration). Or, for any specification of $v_{*}$ (like with the present F-, K-, S- or T-scales), the corresponding physical quantities $m_{*}, \varepsilon_{*}$, or $\boldsymbol{P}_{*}$ can be evaluated for comparison:

$v_{*}=\rho^{-1} \boldsymbol{m}_{*}=\left[2 \rho^{-1} \varepsilon_{*}\right]^{1 / 2}=\left[2 \rho^{-1} \boldsymbol{p}_{*}\right]^{1 / 3}$.

Note that the Mach- or M-scale for wind speeds from zero to the supersonic range is a special case of an E-scale with externally specified $v *$ and will also be referenced as $\mathrm{E}_{\mathrm{M}}$-scale here:

$v(M)=v_{*} M, v_{*}=[\kappa R T]^{1 / 2}=\left[\kappa \rho^{-1} p\right]^{1 / 2} \approx 340.2 \mathrm{~m} \mathrm{~s}^{-1} . E_{M}-$ scale

Herein, $M$ denotes the Mach number, $v_{*}$ is the speed of sound, and $\kappa=c_{p} / c_{v}, R=c_{p}-c_{v}, T$, and $p$ have their usual thermodynamic meanings. The corresponding critical value from Eq. (15) is $\varepsilon_{*}=\kappa / 2 p \approx 70898 \mathrm{~J} \mathrm{~m}^{-3}$, cf. Table 2 .

\subsection{Evaluation and calibration of the E-scale}

I start with the E-scale formulation of the $\mathrm{E}_{\mathrm{F}}$-scale, designed here for the velocity range of the F-scale:

$v(E)=v_{*}(E+1), \quad v_{*}=17.825 \mathrm{~ms}^{-1} . \quad E_{F}-$ scale

No claim is being made that this initial value of $v_{*}$, equalling $v$ $(\mathrm{F}=0)$, is the only possible one, but it is chosen here to facilitate the conversion of existing F-scale rated tornado and damaging wind reports to the E-scale. Relations like Eqs. (16) or (17) for the other scales are given in Section 3.5 below.

As the new E-scale is closely linked to the physical quantities of Eqs. (10a)-(10c), the scaling quantities

$m_{*}=\rho v_{*}, \quad \varepsilon_{*}=\rho / 2 v_{*}^{2}, \quad \boldsymbol{P}_{*}=\rho / 2 v_{*}^{3}$

can be evaluated. Assuming a standard value of $\rho=$ $1.225 \mathrm{~kg} \mathrm{~m}^{-3}$, each $v_{*}$ from Eqs. (16), (17) and Section 3.5 leads to the physical scaling quantities $\mathcal{M}_{*}, \boldsymbol{\varepsilon}_{*}$, and $\boldsymbol{D}_{*}$ as shown in Table 2. For completeness, note that the Mach-scale is calibrated even though not $\boldsymbol{M}_{*}, \varepsilon_{*}$, or $\boldsymbol{P}_{*}$ but $v_{*}$ is specified, as the speed of sound constitutes a critical value itself.

Table 2

Physical quantities $\mathbb{M}_{*}, \varepsilon_{*}$, and $\boldsymbol{D}_{*}$ according to Eq. (18) for the scales under consideration, assuming a standard air density of $1.225 \mathrm{~kg} \mathrm{~m}^{-3}$.

\begin{tabular}{llllllll}
\hline Scale Eq. & \multicolumn{2}{l}{$\begin{array}{l}v_{*} \text { in } \\
\mathrm{m} \mathrm{s}^{-1}\end{array}$} & & $v_{*}^{\prime}$ & $\mathrm{X}_{0} \begin{array}{l}m_{*} \text { in } \\
\mathrm{kg} \mathrm{m}^{-2} \mathrm{~s}^{-1}\end{array}$ & $\begin{array}{l}\mathcal{E}_{*} \text { in } \\
\mathrm{J} \mathrm{m}^{-3}\end{array}$ & $\begin{array}{l}\mathcal{P}_{*} \text { in } \\
\mathrm{W} \mathrm{m}^{-2}\end{array}$ \\
\hline $\mathrm{B}$ & $(2)$ & 0.835 & $v_{*} B^{1 / 2}$ & 0 & 1.02 & 0.43 & 0.36 \\
$\mathrm{~S}$ & $(4)$ & 1.825 & $v_{*}(\mathrm{~S}+6)^{1 / 2}$ & -6 & 2.24 & 2.04 & 3.72 \\
$\mathrm{~T}$ & $(3)$ & 2.362 & $v_{*}(T+4)^{1 / 2}$ & -4 & 2.89 & 3.42 & 8.08 \\
$\mathrm{~F}$ & $(5)$ & 6.302 & $v_{*}(\mathrm{~F}+2)^{1 / 2}$ & -2 & 7.72 & 24.3 & 153 \\
$\mathrm{~K}$ & $(7)$ & 17.825 & $v_{*}(\mathrm{~K}+1)^{1 / 2}$ & -1 & 21.8 & 195 & 3469 \\
$\mathrm{E}_{\mathrm{B}}$ & $(20)$ & 2.893 & $v_{*}$ & 0 & 3.54 & 5.13 & 14.8 \\
$\mathrm{E}_{\mathrm{S}}$ & $(21 \mathrm{a})$ & 8.913 & $v_{*}$ & -3 & 10.9 & 48.7 & 434 \\
$\mathrm{E}_{\mathrm{T}}$ & $(21 \mathrm{~b})$ & 8.913 & $v_{*}$ & -2 & 10.9 & 48.7 & 434 \\
$\mathrm{E}_{\mathrm{F}}$ & $(17)$ & 17.825 & $v_{*}$ & -1 & 21.8 & 195 & 3469 \\
$\mathrm{E}_{\mathrm{M}}$ & $(16)$ & 340.223 & $v_{*}$ & 0 & 417 & 70,898 & $2.412 \times 10^{7}$ \\
\hline
\end{tabular}


Future calibration of the E-scales is possible, provided specific values of either $\boldsymbol{m}_{*}, \varepsilon_{*}$, or $\boldsymbol{p}_{*}$ are found to be significant, for example from statistical modelling or wind engineering studies. From the statistical modelling of tornado intensity distributions, Dotzek et al. (2005) showed that tornado intensities are exponentially distributed over massspecific kinetic energy $v^{2}$. An exponential distribution implies the presence of a distinguished scaling law with a characteristic decay rate $\propto v_{0}^{-2}$. The $v_{0}$-values reported by Dotzek et al. (2005) were approximately $40 \mathrm{~m} \mathrm{~s}^{-1}$, corresponding to $\varepsilon_{*} \sim 1000 \mathrm{~J} \mathrm{~m}^{-3}$ from Eq. (18). Interestingly, virtually the same energy scale of $\sim 1000 \mathrm{~J} \mathrm{~kg}^{-1}$ was derived by Schielicke and Névir (2009-this issue) and shown to apply for a wide range of atmospheric vortices from tornadoes to tropical and extratropical cyclones. Further proof of a universal energy scale $\varepsilon_{*}$ of about $1000 \mathrm{~J}$ per unit mass or per unit volume could also provide a foundation to calibrate the E-scales. Once such scaling values have been identified, the E-scales introduced here could easily be adjusted because of their linear $v(\mathrm{E})$ relation.

This would hold even in the case of regional specification of scaling quantities $\boldsymbol{m}_{*}, \boldsymbol{\varepsilon}_{*}$, or $\boldsymbol{P}_{*}$ accounting for characteristic differences in building standards between the U.S.A. and Europe, for instance. Such calibration or readjustments could be performed without changing the analytical framework presented here, but that would imply to give up using one worldwide applicable form of the E-scale. This is not advocated in the present paper. As outlined in the discussion, having one internationally used E-scale relation and complementing it by regional damage descriptions or insurancerelated metrics like loss ratios (cf. Dotzek et al., 2003) appears more practicable.

\subsection{Conversion of the F-scale to the E-scale ( $E_{F}$-scale)}

To gain acceptance for the new E-scale, existing data based on e. g. F- or T-scale ratings should be readily convertible to the E-scale and also keep the workload for rerating recorded events manageable. The conversion procedure for the F-scale is illustrated here and the results are shown in Table 3.

Any existing scale obeying Eq. (1) can be converted into the E-scale of Eq. (13) and vice versa by the follow-

\section{Table 3}

Conversion of $\mathrm{F}$ - to $\mathrm{E}_{\mathrm{F}}$-scale and $\mathrm{E}_{\mathrm{F}}$ - to F-scale thresholds and classes using values $v_{{ }_{, E}}=17.825 \mathrm{~m} \mathrm{~s}^{-1}$ and $v_{*, F}=6.302 \mathrm{~m} \mathrm{~s}^{-1}$ according to Eqs. (19a), (19b).

\begin{tabular}{|c|c|c|c|c|c|c|c|}
\hline \multicolumn{4}{|c|}{$\mathrm{F}$ - to $\mathrm{E}_{\mathrm{F}}$-scale } & \multicolumn{4}{|c|}{$\mathrm{E}_{\mathrm{F}}$ - to $\mathrm{F}$-scale } \\
\hline $\mathrm{F}$ & $v(\mathrm{~F})$ in $\mathrm{m} \mathrm{s}^{-1}$ & $\mathrm{E}_{\mathrm{F}}^{\prime}$ & $E_{F}$ integer & $\mathrm{E}_{\mathrm{F}}$ & $v(\mathrm{E})$ in $\mathrm{m} \mathrm{s}^{-1}$ & $\mathrm{~F}^{\prime}$ & $F$ integer \\
\hline$\overline{-2}$ & 0.0 & -1.00 & -1 & -1 & 0.0 & -2.00 & -2 \\
\hline-1 & 6.3 & -0.65 & -1 & 0 & 17.8 & 0.00 & 0 \\
\hline 0 & 17.8 & 0.00 & 0 & 1 & 35.6 & 1.17 & 1 \\
\hline 1 & 32.7 & 0.84 & 1 & 2 & 53.5 & 2.16 & 2 \\
\hline 2 & 50.4 & 1.83 & 2 & 3 & 71.3 & 3.04 & 3 \\
\hline 3 & 70.5 & 2.95 & 3 & 4 & 89.1 & 3.85 & 4 \\
\hline 4 & 92.6 & 4.20 & 4,5 & 5 & 106.9 & 4.60 & 4,5 \\
\hline 5 & 116.7 & 5.55 & 5,6 & 6 & 124.8 & 5.32 & 5 \\
\hline 6 & 142.6 & 7.00 & 7 & 7 & 142.6 & 6.00 & 6 \\
\hline
\end{tabular}

Note that only the F4, F5 classes have to be sub-divided into $\mathrm{E}_{\mathrm{F}} 4, \mathrm{E}_{\mathrm{F}} 5, \mathrm{E}_{\mathrm{F}} 6$ classes in converting $\mathrm{F}$-scale to $\mathrm{E}_{\mathrm{F}}$-scale data. ing transformations between $v(\mathrm{E})=v_{*}\left(\mathrm{E}-\mathrm{E}_{0}\right)$ and the $v(\mathrm{X})$ relation:

$E^{\prime}=X_{*} / \nu_{*}\left(X-X_{0}\right)^{3 / 2}+E_{0}$,

$X^{\prime}=\left[v_{*} / X_{*}\left(E-E_{0}\right)\right]^{2 / 3}+X_{0}$,

wherein $\mathrm{E}$ and $\mathrm{E}_{0}$ denote the $\mathrm{E}$-scale variable and offset, respectively.

Table 3 shows that due to the initial choice of $v_{*}=v(\mathrm{~F}=0)$ in Eq. (17), the $\mathrm{E}_{\mathrm{F}}$-scale thresholds $\mathrm{E}_{\mathrm{F}}-1, \mathrm{E}_{\mathrm{F}} 0$, and $\mathrm{E}_{\mathrm{F}} 7$ correspond to $\mathrm{F}-2$, F0, and F6, respectively. In addition, the $\mathrm{E}_{\mathrm{F}} 3$ and $\mathrm{F} 3$ thresholds are nearly identical. Thus, the $\mathrm{E}_{\mathrm{F}}$-scale has the same upper "end" as the present F-scale and also comprises the same total number of classes as the F-scale, yet it contains only one sub-critical class and hence one more class in the relevant range of present F0 to F5 ratings. The enhanced resolution mainly sets in above the F4 threshold, i.e. the F-scale classes [F4, F5] are mapped to $\left[\mathrm{E}_{\mathrm{F}} 4, \mathrm{E}_{\mathrm{F}} 5, \mathrm{E}_{\mathrm{F}} 6\right]$, and the thresholds for these classes are effectively lowered compared to the F-scale. This is also the intensity range for which the Fujita-scale forum (McDonald, 2002, cf. www.april31974.com/fujita_scale_forum.htm) had claimed the largest demand for improvements in the choice of scale class boundaries.

As a conclusion of Table 3, should a conversion of the US tornado intensity data from $\mathrm{F}$ - to $\mathrm{E}_{\mathrm{F}}$-scale once come on the agenda in the USA, it would mainly require to review the recorded F5 events, which only amounted to roughly 10 per decade in the 20th century (cf. Dotzek et al., 2003). In the same period, about $80 \mathrm{~F} 4$ tornadoes per decade were recorded in the USA, of which only the stronger ones would have to be re-rated to $\mathrm{E}_{\mathrm{F}}$-scale based on the available case information. So even for the world's largest tornado database, the workload involved to adopt the E-scale would indeed remain manageable. ${ }^{3}$

\subsection{Application of the E-scale concept to the B-, T-, and S-scales}

Let's start with the $\mathrm{E}_{\mathrm{B}}$-scale, with the scaling velocity adapted to reproduce the velocity range of the B-scale, that is $v(\mathrm{E} 12)$ equalling $v(\mathrm{~B} 12)$ :

$v(E)=v_{*} E, \quad v_{*}=2.893 \mathrm{~ms}^{-1} . \quad E_{B}-$ scale.

If one uses $X_{0}=[-1,0]$ exclusively, then E-scale equivalents to finely-resolved scales with a high wind speed threshold (like S- or T-scale) are not feasible. Consequently, the requirement $X_{0}=-1$ is relaxed in these cases to present the following $\mathrm{E}_{\mathrm{S}^{-}}$and $\mathrm{E}_{\mathrm{T}^{-}}$-Scales, illustrating again their similarity:

$$
\begin{array}{lll}
v(E)=v_{*}(E+3), & v_{*}=8.913 \mathrm{~ms}^{-1} . & E_{S}-\text { scale } \\
v(E)=v_{*}(E+2), & v_{*}=8.913 \mathrm{~ms}^{-1} . & E_{T}-\text { scale }
\end{array}
$$

Table 2 reviews the characteristic quantities of the $E_{B}$, $E_{S}$, and $\mathrm{E}_{\mathrm{T}}$-scales.

\footnotetext{
${ }^{3}$ Unfortunately, this effort would be severely hampered by an apparent lack of necessary metadata in the US record of tornado and other severe storm reports based on NCDC's Storm Data and the derived NOAA-SPC's severe weather database files; see www.spc.noaa.gov/wcm/SPC_severe_database_description.pdf. The reports contain quantitative information, yet without metadata on the types or reliability of sources.
} 
The B-scale has never been used in the USA as widely as in Europe, and also in Europe, it is being used less frequently now. Hence, I anticipate that also the $\mathrm{E}_{\mathrm{B}}$-scale would not be widely applied, but that for ordinary wind speeds, the meteorological community will increasingly rely on using wind speed values directly, probably augmented by specification of a variance interval.

The $E_{T}$ and $E_{S}$-scales differ only in their offsets $E_{0}$ (either -3 or -2 ), such that there is no compelling reason to maintain both scales. Either of the scales could successfully be applied to winds in tropical cyclones (or to tornadoes if a very fine partitioning of the scale is desired). Looking at the relation of the $E_{T}$ and $E_{S}$-scale classes to those of the $E_{F}$-scale

$2 E_{F}=E_{S}+1$,

$2 E_{F}=E_{T}$,

the relation between $\mathrm{E}_{\mathrm{F}}$ and $\mathrm{E}_{\mathrm{T}}$-scale is more straightforward, as two steps on the $\mathrm{E}_{\mathrm{T}}$-scale exactly correspond to one step on the $\mathrm{E}_{\mathrm{F}}$-Scale (recall that this holds only in an approximate way for the present F- and T-scales). It would be a step forward in the climatological recording of tropical cyclones around the globe if the $\mathrm{E}_{\mathrm{T}}$-scale were implemented for intensity ratings of these extreme events worldwide, and not only over the Atlantic basin.

\section{Discussion}

The E-scale concept as presented in this paper is physically straightforward and meets several requirements which had been set up (cf. Forbes and Wakimoto, 1983; Doswell and Burgess, 1988) especially in relation to the Fujita scale: (i) the $\mathrm{E}_{\mathrm{F}}$-scale has a finer resolution at the upper end of the possible range of tornadic wind speeds, mapping the two classes F4 and F5 to three new classes E4, E5, E6; (ii) by presently maintaining the upper bound of the F5 class ( $142.6 \mathrm{~m} \mathrm{~s}^{-1}$ ) also for the high end of the E6 class, the threshold speeds for present F4 and F5 tornadoes are lowered; (iii) there is only one sub-critical wind speed class with the $\mathrm{E}_{\mathrm{F}}$-scale, but instead one more class in the relevant wind speed range, thus also allowing for improved statistical modelling of tornado intensity distributions (cf. Dotzek et al., 2005). On the one hand, one additional class in the intensity range of significant (F2 or higher) tornadoes will help to better resolve the far wing of the tornado intensity distribution with its necessary steep decrease towards the apparent upper limit of tornado energy. On the other hand, to have only one class more would not lead to possible implication of too much precision in the high ratings, as sometimes argued with respect to the T-scale with its doubled number of classes compared to the F-scale.

One major strength of the E-scales is that they allow for a calibration by specifying relevant critical values for the quantities $\boldsymbol{M}_{*}, \varepsilon_{*}$, or $\mathcal{P}_{*}$ ( or $v_{*}$ itself as in the special case of the Mach scale $\left.E_{M}\right)$. Note that all these quantities depend on air density $\rho$, so in principle, variations in wind loads from compressibility effects or for tornadoes over high terrain are included in the E-scales.

Relying on physical quantities was also one motivation for Emanuel $(2005,2007)$ to develop the Power Dissipation Index (PDI) for tropical cyclones. It is evident that an E-scale based on the scaling quantity $\boldsymbol{P}_{*}$ is directly linked to the integral measure
PDI. Also in light of the discussion in Section 3.3, to advance from scales based on observed wind damage to the E-scale would be a similar step forward as switching from the Mercalli to the Gutenberg-Richter earthquake scale in geophysics. Mercalli's scale was based on eyewitness and damage reports, with shortcomings very similar to those encountered in present wind event ratings. The Gutenberg-Richter scale, however, is an energy scale. Adopting the E-scale and applying it to the PDI concept could provide a way to measure the total energy expended in a wind event, and this would be much more valuable than any present point measurement or damage assessment. Interestingly, the new Environmental Seismic Intensity scale (ESI 2007, see Guerrieri and Vittori, 2007) also takes such an integrative approach and combines the previously applied earthquake scales with a new description of damage indicators from the natural environment without man-made structures.

When looking at the history of the various scales, it is not really obvious how the $3 / 2$ exponent entered the velocityscale relations. In design of the $v(F)$ relation by Fujita (1971), he provided the justification that higher scale resolution in $v$ was desired for low values of $\mathrm{F}$, but apparently he also aimed at extrapolating the $\bar{v}(B)$ relation of the Beaufort scale (cf. McDonald, 2001). The practical application of the F-scale over several decades showed, however, that the relatively fine resolution of the F-scale below $\mathrm{F} 3$ intensity resulted in a too coarse specification of the wind speed intervals above F3, caused by the $3 / 2$ exponent.

This is avoided by the E-scales which always entail linear velocity-scale relationships. Within the present paper, the choice of the initial $v *$-values was made for compatibility of the main $\mathrm{E}_{\mathrm{F}}$-scale thresholds to those of the F-scale, and thus to facilitate conversion of present ratings based on F-scale to the E-scale definitions.

Formally, the E-scales lead to a binning of wind speeds in the velocity-scale relation. Carrying this approach to the extremes, one might argue to omit the use of scales altogether and simply use wind speed instead of velocity classes and to provide estimates of peak winds and their variance. This is certainly an option for the $\mathrm{E}_{\mathrm{B}}$-scale, and in fact use of the Beaufort scale in broadcast meteorology becomes more and more infrequent nowadays and is replaced by forecast wind speeds.

However, for high wind speeds like in tropical or extratropical cyclones, or in downbursts and tornadoes, a binning will remain necessary, practical, and convenient. The achievable accuracy of wind speed measurements or deductions from damage assessments is not high enough to support specification of "the" maximum velocity. And besides, it will continue to be more descriptive in weather forecasts, watches or warnings to speak of a "category-4 hurricane" or an "F3 tornado", or their equivalents in E-scale terminology. A similar argument holds for aeronautics, where the Mach scale (as a special case of an E-scale) is also more convenient to use than instantaneous velocities.

One big advantage of the E-scales is that they are wind speed scales which bin the physically possible range of peak wind speeds by the $v(\mathrm{E})$ relation. Therefore, the E-scales are applicable worldwide, which is an essential prerequisite for building a homogeneous climatology of high wind events and for studying climate change impacts on severe storms as deemed high on the agenda by IPCC (2007).

Yet, some open points remain, despite the evident improvement in wind speed scale design based on the E-scales: Both 


\begin{tabular}{|c|c|c|c|c|c|c|c|c|}
\hline \multirow{2}{*}{\multicolumn{2}{|c|}{$\begin{array}{l}\text { Damage: } \\
\text { f scale }\end{array}$}} & $\begin{array}{l}\text { Little } \\
\text { Damage }\end{array}$ & $\begin{array}{l}\text { Minor } \\
\text { Damage }\end{array}$ & $\begin{array}{l}\text { Roof } \\
\text { Gone }\end{array}$ & $\begin{array}{l}\text { Walls } \\
\text { Collapse }\end{array}$ & $\begin{array}{l}\text { Blown } \\
\text { Down }\end{array}$ & $\begin{array}{l}\text { Blown } \\
\text { Away }\end{array}$ & \\
\hline & & fo & $\mathrm{f} 1$ & $\mathrm{f} 2$ & f3 & $\mathrm{f} 4$ & f5 & \\
\hline \multicolumn{2}{|c|}{ Windspeed: } & $\mathrm{m} / \mathrm{s}$ & \multicolumn{2}{|c|}{50} & & \multicolumn{2}{|c|}{117} & 143 \\
\hline \multirow{2}{*}{\multicolumn{2}{|c|}{ F scale }} & F0 & F1 & $\mathrm{F} 2$ & $\mathrm{~F} 3$ & $\mathrm{~F} 4$ & F5 & \\
\hline & & $\mathrm{km} / \mathrm{h}$ & \multicolumn{3}{|c|}{181} & \multicolumn{2}{|c|}{420} & 513 \\
\hline \multicolumn{9}{|c|}{$\nabla$} \\
\hline Weak Outbuilding & -3 & f3 & $\mathrm{f} 4$ & f5 & f5 & f5 & f5 & \\
\hline Strong Outbuilding & -2 & f2 & f3 & f4 & f5 & f5 & f5 & \\
\hline Weak Framehouse & -1 & f1 & $\mathrm{f} 2$ & $\mathrm{f} 3$ & $\mathrm{f} 4$ & f5 & f5 & \\
\hline Strong Framehouse & 0 & F0 & F1 & $\mathrm{F} 2$ & F3 & $\mathrm{F} 4$ & F5 & \\
\hline Brick Structure & 1 & - & fo & f1 & $\mathrm{f} 2$ & f3 & $\mathrm{f} 4$ & \\
\hline Concrete Building & 2 & - & - & fo & f1 & $\mathrm{f} 2$ & f3 & \\
\hline
\end{tabular}

Fig. 2. The f-scale matrix (adapted from Fujita, 1992) describing the relation of F-scale wind speeds (intensity) and structure-dependent damage (f-scale). For the building type "strong frame house" in the USA, the F- and f-scale ratings are considered identical.

national variations in building codes and regional or even local variety in building practice or individual structural strength and maintenance status will lead to a spectrum of observed damage for the same given wind speed value or scale class. In addition, the duration of the high wind speeds acting on a given structure plays a role for the degree of damage. This holds in particular for the long-lived high wind regime in tropical and extratropical cyclones, but less so for the quick passage of tornadoes and damaging wind gusts. These principle problems with their inherent uncertainties will likely persist as long as wind speeds will be estimated from damage for practical reasons. The Escales are expected to mitigate these problems, as they divide the wind speed range into evenly wide velocity bins compared to the nonlinear increase of wind speed (and degree of damage) intervals known from the presently applied scales.

The f-scale matrix (Fujita, 1992; cf. McDonald, 2001) as shown in Fig. 2 aimed at addressing this for the USA building standards by distinguishing between wind speed (F-scale) and typical damage (f-scale) for a given structure at that wind speed. The f-scale concept is another example of providing national damage descriptions for a universal, worldwideapplicable wind speed scale (cf. the other example for Europe mentioned in the introduction). The f-scale approach provided more detail than the original US damage description over Fscale, and remained at a manageable level of complexity.

Yet the f-scale never gained widespread acceptance, and mobile Doppler radar measurements of near-surface winds at or slightly above the F6 threshold (cf. Monastersky, 1999; Potter, 2007) stoked fears of exaggerated media coverage of potential F6-tornadoes in the USA. ${ }^{4}$ Thus, discussion on improving the Fscale design continued in the Fujita-scale forum (McDonald,

\footnotetext{
4 The adequacy of these concerns may of course be debated. Besides, they are a problem of warning decision and public perception in the USA only, and seemingly irrelevant elsewhere.
}

2002, cf. www.april31974.com/fujita_scale_forum.htm) and finally led to the proposition of an "Enhanced Fujita-scale" (EF-scale, McDonald et al., 2004) which became the NOAAapproved tornado wind speed scale in the USA from February 2007 on, in spite of an ongoing discussion about the new scale (cf. Doswell, 2006; McCarthy et al., 2006; Potter, 2007; Doswell et al., 2009-this issue).

In brief, the characteristics of the EF-scale are to retain the numbering of the F-scale classes and in general also the related typical damage, but to specify (based on an "expert elicitation") significantly lower thresholds for strong and violent tornadoes. Above 200 miles $\mathrm{h}^{-1}$ (89.4 $\left.\mathrm{m} \mathrm{s}^{-1}\right)$, no further distinction by the EF-scale is made. The assignment of an EF-scale is based solely on the observed US-type damage, described in much detail by a matrix of 28 Damage Indicators (DI) and a set of Degrees of Damage (DOD) for each DI. The fact that the DIs now also consider tree damage is a good point. This is a field which has only recently been addressed in the USA (e. g., Foster and Boose, 1992; Dyer and Baird, 1997; Cooper-Ellis et al., 1999; Peterson, 2003; Fumiko et al., 2006; Papaik and Canham, 2006; Holland et al., 2006), but has always been taken into account in Europe (cf. Martins, 1850; Wegener, 1917; Letzmann, 1923, 1939, Koschmieder and Letzmann, 1939; Rossmann, 1959; Peterson, 1992a,b; Hubrig, 2004, Dotzek et al., 2008). Yet apparently, few of the specialists in tree damage research have been involved in the specifications of DODs for tree species.

Besides, the damage description (and hence also the "elicited" threshold speeds) of the present EF-scale are endemic to the USA and not applicable worldwide (despite one case study for Europe, Marshall and Robinson, 2006), and the EF-scale decision matrix with its many DIs and DODs is also much more complicated to disseminate and apply than e.g. Fujita's f-scale approach (cf. LaDue and Mahoney, 2006). However, to assign damage descriptions is not a challenge limited to the EF-scale, but would also apply to any other 
damage scale which aims to assess wind speed from observed damage.

In light of the derivation of the E-scales in this paper, in particular the subjective assignment of EF wind speed thresholds corresponding to a certain level of damage seems questionable. In E-scale terminology, one should not adapt $v_{*}$ to certain national building type or other man-made structures, but proceed the opposite way and provide a worldwide applicable wind speed scale based on physical principles with nationally-adapted damage descriptions which may well be as detailed as with the EF-scale, should this high level of detail prove to be feasible.

A key point to be made here again is the importance of defining (and abiding by) an internationally accepted specification of wind speed scales for high wind events like (tropical) cyclones, convective straight-line winds and tornadoes. This paper substantiates why the E-scale concept is a good candidate to synthesise the present variety of empirical wind speed scales. The effort to identify a large number of damage indicators and to develop detailed degrees of damage for each of them by the EF-scale designers may turn out to be valuable to complement an international E-scale wind speed range by the necessary regional damage descriptions for this range of wind speeds, as advocated in this paper.

There are some conceivable future developments which must definitely be avoided: To apply a mixture of different scales or locally adapted threshold wind speeds in one country, or to apply different scales across countries - like having the EF-scale in the USA and the traditional F-scale in nearly all other countries, even neighbouring ones like Canada. The introduction of the EF-scale in the USA is paralleled by a questioning of also other traditional scales like the S-scale (e. g., Kantha, 2006; Powell and Reinhold, 2007a), or by a conceptual unification of the various scales by the E-scale presented here. While the present search for improved wind scales is certainly fruitful, it should soon lead to an agreement on worldwide standards, in order not to endanger the international comparability of intensity ratings.

One type of homogenised damage assessment is often applied in the insurance industry. Here, the metric of damage is the average loss ratio $L$ for man-made structures in a certain region:

L in $\%=100 \frac{\text { monetary damage }}{\text { reinstatement value }}$.

Often, a further distinction is made between lightstructure $(L-)$ and solid $(L+)$ buildings. Such typical loss ratios in Central Europe have been linked to the F-scale in cooperation with Munich Re (cf. Dotzek et al., 2000, 2003). The corresponding values are shown in Table 1.

Yet, even then, some questions remain to be answered on the way to a truly objective wind intensity scale. First to mention are the nearly diametrical viewpoints of wind engineering and atmospheric sciences: While the first group focuses on the minimum wind speeds necessary to cause a certain degree of damage (e. g. Euteneuer, 1970; Golden, 1999), the latter group aims more at the discrete distribution of maximum winds (Brooks and Doswell, 2001; Dotzek et al., 2003; Feuerstein et al., 2005; Dotzek et al., 2005) within the range of wind speeds that are physically possible in tropical cyclones or tornadoes (e. g. Ferrel, 1893; Fiedler and Rotunno, 1986; Emanuel, 1988; Lewellen, 1993; Lewellen et al., 2002; Renno, 2008). In principle, also damage surveys could provide estimates of maximum winds, but this would imply the presence of undamaged or only weakly damaged structures, allowing to infer which wind speeds had apparently not been exceeded during the storm.

Thus verification of wind speed scales at their high end will remain a challenge. Additional future tasks include proper assessment of building and vegetation strength variations and the spatial distribution of peak winds (or damage), both across the storm path (see Brooks, 2004) and vertically in the surface layer to further establish a sound relation between near-surface Doppler radar measurements and observed damage (Dowell et al., 2005; Wurman and Alexander, 2005; Wurman et al., 2007). However, to address these questions is beyond the scope of the present paper.

\section{Conclusions}

This analysis has led to a new type of wind speed scale, named Energy-scale or E-scale due to the coupling of its scaling quantities to wind energy- or energy flux density. Especially the $\mathrm{E}_{\mathrm{F}}$-scale is proposed to serve as a physics-based alternative to the F-scale. Yet, any scale obeying Eq. (13) is an E-scale and bears the following useful properties:

- The E-scale is based on physical scaling quantities and hence allows for calibration;

- The resulting E-scale versus wind speed relations are always linear;

- E-scales rely on class thresholds, not central values. There is no inconsistency between averaged wind speeds and the wind speed resulting from an average of the scale value;

- The $\mathrm{E}_{\mathrm{F}}$-scale comprises the same number of classes as the $\mathrm{F}$ scale, yet only one sub-critical class and thus one more class in the relevant range F0 to F5. The enhanced resolution mainly sets in above the F4 threshold, i. e. the classes [F4, F5] are mapped to [E4, E5, E6], so F-scale data would be easy to convert to $\mathrm{E}_{\mathrm{F}}$-Scale, if the metadata of US storm databases would only allow for this;

- The F-scale thresholds F-2, F0, and F6 are exactly mapped to E-1, E0, and E7, while the F3 and E3 thresholds are nearly identical;

- The E-scale concept can help to unify and reduce the present plethora of different scales for winds from gale to hurricane intensity. In particular, there is no compelling reason to distinguish the $\mathrm{E}_{\mathrm{T}^{-}}$and $\mathrm{E}_{\mathrm{S}^{-}}$-scales, and due to its particularly simple relation to the $\mathrm{E}_{\mathrm{F}}$-scale, the $\mathrm{E}_{\mathrm{T}}$-scale appears bestsuited for application to tropical cyclones worldwide;

- In the present scientific discussion about appropriate and practicable high wind scales, it will be important to reach an agreement on worldwide standards, in order not to endanger the international comparability of intensity ratings.

- To include variations in building characteristics, one should not adapt the wind speed ranges to certain national building characteristics. Instead, one worldwide applicable wind speed scale based on physical principles should be complemented by nationally-adapted damage descriptions. The E-scale concept can provide the basis for such a standardised wind speed scale. 
The next step would be calibration of the E-scales of which only the Mach-scale $E_{M}$ is presently calibrated. Here, further input from statistical modelling, wind engineering and atmospheric remote sensing is needed to define relevant values of $\boldsymbol{M}_{*}, \varepsilon_{*}$, or $\boldsymbol{p}_{*}$ to consistently derive the appropriate scaling velocities $v_{*}$. Should this be accomplished in the future, conversion among recalibrated E-scales would be easy due to their linear wind speed versus scale relationship.

\section{Acknowledgements}

The work on the E-scale concept started in the Christmas break 2004/2005, kindly supported by the patience of my family. I am further grateful to Chuck Doswell for stimulating discussions on this matter and to Jeff Trapp, Kerry Emanuel and Roger Edwards for helpful comments. Two anonymous referees provided detailed and insightful suggestions to improve the manuscript, which I appreciated a lot. This work was partly funded by the German Ministry for Education and Research (BMBF) under contract 01LS05125 in the project RegioExAKT (Regional Risk of Convective Extreme Weather Events: User-oriented Concepts for Climatic Trend Assessment and Adaptation, www regioexakt.de) within the research programme klimazwei.

\section{Appendix A. Computation of mean velocities in present scale classes}

Due to the nonlinear velocity-scale relation of Eq. (1), there are three possible ways to compute an average velocity in each scale class, exemplified here for the F-scale of Eq. (5): a) Minimum estimator:

$v_{c}=v(\bar{F})=v\left(F^{\prime}+0.5\right)=v_{0}(F+2.5)^{3 / 2}$

b) Integral average:

$$
\begin{aligned}
<v> & =\frac{1}{\Delta F} \int_{F}^{F+1} v\left(F^{\prime}\right) d F^{\prime}, \quad \Delta F=1 ; \\
& =2 / 5 v_{0}\left[(F+3)^{5 / 2}-(F+2)^{5 / 2}\right] .
\end{aligned}
$$

c) Maximum estimator:

$$
\begin{aligned}
v_{m}=\bar{v}(F) & =1 / 2\left[v\left(F^{\prime}\right)+v\left(F^{\prime}+1\right)\right] \\
& =1 / 2 v_{0}\left[(F+2)^{3 / 2}+(F+3)^{3 / 2}\right] .
\end{aligned}
$$

The relation $v_{c}<<v><v_{m}$ always holds. However, the absolute differences between these values become negligible for nonnegative F-scale classes. In general, Eq. (A2b) has been used, except for those cases in which explicitly $v(\bar{F})$ from Eq. (A1) was implied.

\section{References}

Betz, A., 1926: Wind-Energie und ihre Ausnutzung durch Windmühlen (Wind energy and its exploitation by windmills). Aus Naturwissenschaft und Technik, Heft 2, Vandenhoeck und Ruprecht Verlag, Göttingen, 64 pp. [In German].

Brooks, H.E., 2004. On the relationship of tornado path length and width to intensity. Weather Forecasting 19, 310-319.

Brooks, H.E., Doswell, C.A., 2001. Some aspects of the international climatology of tornadoes by damage classification. Atmos. Res. 56, 191-202.
Cooper-Ellis, S., Foster, D.R., Carlton, G., Lezberg, A., 1999. Forest response to catastrophic wind: Results from an experimental hurricane. Ecology 80, 2683-2696.

Doswell, C.A., 2006: Thoughts on the new EF-scale: Tornado rating consistency and the QRT. Online at www.flame.org/ cdoswell/EFscale_rant.html, as of: 13 May 2006.

Doswell, C.A., Burgess, D.W., 1988. On some issues of United States tornado climatology. Mon. Weather Rev. 116, 495-501.

Doswell, C.A., Brooks, H.E., Dotzek, N., 2009. On the implementation of the Enhanced Fujita scale in the USA. Atmos. Res. 93, 554-563 (this issue).

Dotzek, N., Berz, G., Rauch, E., Peterson, R.E., 2000. Die Bedeutung von Johannes P. Letzmanns "Richtlinien zur Erforschung von Tromben, Tornados, Wasserhosen und Kleintromben" für die heutige Tornadoforschung (The relevance of Johannes P. Letzmann's "Guidelines for research on tornadoes, waterspouts, and whirlwinds" for contemporary tornado research). Meteorol. Z. 9, 165-174 (In German, available at essl. org/people/dotzek/papers.htm).

Dotzek, N., Grieser, J., Brooks, H.E., 2003. Statistical modeling of tornado intensity distributions. Atmos. Res. 67-68, 163-187.

Dotzek, N., Kurgansky, M.V., Grieser, J., Feuerstein, B., Névir, P., 2005. Observational evidence for exponential tornado intensity distributions over specific kinetic energy. Geophys. Res. Lett. 32, L24813. doi:10.1029/ 2005 GL024583.

Dotzek, N., Peterson, R.E., Feuerstein, B., Hubrig, M., 2008. Comments on “A simple model for simulating tornado damage in forests". J. Appl. Meteor. Climatol. 47, 726-731.

Dowell, D.C., Alexander, C.R., Wurman, J.M., Wicker, L.J., 2005. Centrifuging of hydrometeors and debris in tornadoes: radar-reflectivity patterns and wind-measurement errors. Mon. Weather Rev. 133, 1501-1524.

Dyer, J.M., Baird, P.R., 1997. Wind disturbance in remnant forest stands along the prairie-forest ecotone, Minnesota, USA. Plant Ecol. 129, 121-134.

Emanuel, K.A., 1988. The maximum intensity of hurricanes. J. Atmos. Sci. 45, 1143-1155.

Emanuel, K., 2005. Increasing destructiveness of tropical cyclones over the last 30 years. Nature 436, 686-688. doi:10.1038/nature03906.

Emanuel, K., 2007. Environmental factors affecting tropical cyclone power dissipation. J. Climate 20, 5497-5509.

Euteneuer, G.A., 1970. Aerodynamische Betrachtungen im Pforzheimer Wirbelsturm vom 10. Juli 1968 (Aerodynamic considerations for the Pforzheim tornado of 10 July 1968). Arch. Meteorol. Geophys. Bioklimatol. A19, 355-371 (In German)

Ferrel, W., 1893. A popular treatise on the winds, 2nd ed. MacMillan and Co., London. 505 pp.

Feuerstein, B., Dotzek, N., Grieser, J., 2005. Assessing a tornado climatology from global tornado intensity distributions. J. Climate. 18, 585-596.

Fiedler, B.H., Rotunno, R., 1986. A theory for the maximum windspeeds in tornado-like vortices. J. Atmos. Sci. 43 (21), 2328-2340.

Forbes, G.S., Wakimoto, R.M., 1983. A concentrated outbreak of tornadoes, downbursts and microbursts, and implications regarding vortex classification. Mon. Weather Rev. 111, 220-235.

Foster, D.R., Boose, E.R., 1992. Patterns of forest damage resulting from catastrophic wind in central New England, USA. J. Ecol. 80, 79-98.

Fujita, T.T., 1971. Proposed characterization of tornadoes and hurricanes by area and intensity. SMRP research paper, vol. 91. University of Chicago. 42 pp.

Fujita, T.T., 1981. Tornadoes and downbursts in the context of generalized planetary scales. J. Atmos. Sci. 38, 1511-1534.

Fujita, T.T., 1992. Mystery of Severe Storms. Chicago University Press, Chicago. 298 pp.

Fujita, T.T., Pearson, A.D., 1973. Results of FPP classification of 1971 and 1972 tornadoes. Proc. 8th Conf. on Severe Local Storms, Denver. Amer. Meteor. Soc., Boston, pp. 142-145.

Fumiko, S., Kiyoshi, S., Ramon, A.J., Michael, P., 2006. Tornado damage of Quercus stellata and Quercus marilandica in the Cross Timbers, Oklahoma, USA. J. Veg. Sci. 17, 347-352.

Golden, J.H., 1999. Tornadoes. In: Pielke Jr., R., Pielke Sr., R. (Eds.), Storms, vol. II. . Routledge Hazards and Disasters Ser., vol. 2. Routledge, London, pp. 103-132. 345 pp.

Guerrieri, L., Vittori, E. (Eds.), 2007. Intensity Scale ESI 2007. Mem. Descr. Carta Geologica d'Italia, vol. 74. Servizio Geologico d'Italia - Dipartimento Difesa del Suolo, APAT, Rome, Italy. 53 pp.

Holland, A.P., Riordan, A.J., Franklin, E.C., 2006. A simple model for simulating tornado damage in forests. J. Appl. Meteor. Climatol. 45, 1597-1611.

Hsu, S.A., Blanchard, B.W., 2008. Comment on "Tropical cyclone destructive potential by integrated kinetic energy”. Bull. Amer. Meteor. Soc. 89 (10), 1575-1576.

Hubrig, M., 2004. Analyse von Tornado- und Downburst-Windschäden an Bäumen (Analysis of tornado and downburst wind damage to trees). Forst und Holz 59, 78-84 (In German, available at essl.org).

IPCC (Ed.), 2007. Climate Change 2007: The Physical Science Basis. Cambridge University Press, Cambridge. 996 pp. 
Kantha, L., 2006. Time to replace the Saffir-Simpson hurricane scale? Eos, Trans. - Am. Geophys. Union 87, 3. doi:10.1029/2006E0010003.

Kantha, L., 2008. Comment on "Tropical cyclone destructive potential by integrated kinetic energy”. Bull. Am. Meteor. Soc. 89 (2), 219-221.

Kelly, D.L., Schaefer, J.T., McNulty, R.P., Doswell, C.A., Abbey Jr., R.F., 1978. An augmented tornado climatology. Mon. Weather Rev. 106, 1172-1183.

Koschmieder, H., Letzmann, J.P., , 1939: Erforschung von Tromben (Research on tornadoes). Int. Meteor. Org., Klimatol. Komm., Protokolle der Tagung in Salzburg, 13.-17. September 1937, Publ. 38, Leyde, Anlage XI, 85-90. [In German, with commenting English letters by J.B. Kincer, U. S. Weather Bureau, available at essl.org/pdf/Letzmann1939/Koschmieder-Letzmann1939.pdf]

LaDue, J.G., Mahoney, E.A., 2006. Implementing the new Enhanced Fujita scale within the NWS. Preprints, 23rd Conf. on Severe Local Storms, St. Louis, 6-10 November 2006. Amer. Meteor. Soc., Boston. 4 pp. [Available at ams.confex.com/ams/23SLS/techprogram/paper_115420.htm].

Letzmann, J.P., 1923: Das Bewegungsfeld im Fuß einer fortschreitenden Wind- oder Wasserhose (The flow field at the base of an advancing tornado). Ph.D. Thesis, University Helsingfors. Acta et Commentationes Universitatis Dorpatensis AVI.3, C. Mattiesen Verlag, Dorpat, 136 pp. [In German, available at essl.org/pdf/Letzmann1923/Letzmann1923.pdf]

Letzmann, J.P., 1939: Richtlinien zur Erforschung von Tromben, Tornados, Wasserhosen und Kleintromben (Guidelines for research on tornadoes, waterspouts, and whirlwinds). Anlage XI, 91-110. In: Secretariat de l'Organisation Météorologique Internationale (Ed.), Klimatologische Kommission, Protokolle der Tagung in Salzburg, 13.-17. September 1937. IMO Publ. Nr. 38, Edouard Ijdo, Leyde, 149 pp. [In German, available at essl.org/pdf/Letzmann1939/Letzmann1939.pdf].

Lewellen, W.S., 1993. Tornado vortex theory. In: Church, C., Burgess, D. Doswell, C., Davies-Jones, R. (Eds.), The Tornado: Its Structure, Dynamics, Prediction, and Hazards. Geophys. Monogr., vol. 79. Amer. Geophys. Union, Washington, pp. 19-39. 637 pp.

Lewellen, W.S., Xia, J., Lewellen, D.C., 2002. Transonic velocities in tornadoes? Preprints 21st Conf. on Severe Local Storms, Austin. Amer. Meteor. Soc., Boston, pp. 535-538.

Marshall, T.P., Robinson, S., 2006. Birmingham U.K. tornado: 28 July 2005. Preprints, 23rd Conf. on Severe Local Storms, St. Louis, 6-10 November 2006. Amer. Meteor. Soc., Boston. 6 pp. [Available at ams.confex.com/ ams/23SLS/techprogram/paper_115203.htm].

Martins, C., 1850. Anweisung zur Beobachtung der Windhosen oder Tromben (Guidelines to tornado observation). Poggend. Ann. Phys. 81, 444-467 (In German).

McCarthy, D., Schaefer, J.T., Edwards, R., 2006. What are we doing with (or to) the F-Scale? Preprints, 23rd Conf. on Severe Local Storms, St. Louis, 6-10 November 2006. Amer. Meteor. Soc., Boston. 5 pp. [Available at ams. confex.com/ams/23SLS/techprogram/paper_115260.htm].

McDonald, J.R., 2001. T. Theodore Fujita: his contribution to tornado knowledge through damage documentation and the Fujita scale. Bull. Am. Meteor. Soc. 82, 63-72.

McDonald, J.R., 2002. Development of an enhanced Fujita scale for estimating tornado intensity. Preprints, 21st Conf. on Severe Local Storms, Austin. Amer. Meteor. Soc., Boston, pp. 174-177. [Available at ams.confex.com/ ams/SLS_WAF_NWP/21SLS/abstracts/47974.htm].

McDonald, J.R., Mehta, K.C., Mani, S., 2003. F-scale modification process and proposed revisions. Preprints, 83rd AMS Annual Meeting: Symposium on the F-Scale and Severe-Weather Damage Assessment, Long Beach. Amer Meteor. Soc., Boston. 5 pp. [Available at ams.confex.com/ams/annual2003/ FSCALE/abstracts/53999.htm].

McDonald, J.R., Forbes, G.S., Marshall, T.P., 2004. The enhanced Fujita (EF) scale Preprints 22nd Conf. on Severe Local Storms, Hyannis. Amer. Meteor. Soc. Boston. 7 pp. [Available at ams.confex.com/ams/11aram22sls/techprogram/paper_81090.htm].

Meaden, G.T., 1976. Tornadoes in Britain: their intensities and distribution in space and time. J. Meteor. 1, 242-251.
Meaden, G.T., Kochev, S., Kolendowicz, L., Kosa-Kiss, A., Marcinoniene, I., Sioutas, M., Tooming, H., Tyrrell, J., 2007. Comparing the theoretical versions of the Beaufort scale, the T-scale and the Fujita scale. Atmos. Res. 83, 446-449.

Müller, G., 1979. Probleme der Umrechnung von Windstärkeangaben nach der Beaufortskala und Windgeschwindigkeitswerten (Procedures for the conversion of wind force data based on the Beaufort-scale into values of wind velocity). Meteorol. Rundsch. 32, 7-12 (In German).

Monastersky, R., 1999. Oklahoma tornado sets wind record. Sci. News 155 (20) [Available at www.sciencenews.org/sn_arc99/5_15_99/fob1.htm].

NOAA-NWS (Ed.), 2003. A Guide to F-scale Damage Assessment. U.S. Dept. of Commerce, Washington. 94 pp.

Papaik, M.J., Canham, C.D., 2006. Species resistance and community response to wind disturbance regimes in northern temperate forests. J. Ecol. 94, 1011-1026.

Peterson, C.J., 2003. Factors influencing treefall risk in tornadoes in natural forests. Preprints, 83rd AMS Annual Meeting: Symposium on the F-Scale and Severe-Weather Damage Assessment, Long Beach. Amer. Meteor. Soc., Boston. CD-ROM, P 3.1., 5 pp. [Available at ams.confex.com/ams/ annual2003/FSCALE/abstracts/53292.htm].

Peterson, R.E., 1992a. Johannes Letzmann: a pioneer in the study of tornadoes. Weather Forecast. 7, 166-184.

Peterson, R.E., 1992b. Letzmann's and Koschmieder's "Guidelines for research on funnels, tornadoes, waterspouts and whirlwinds". Bull. Am. Meteor. Soc. 73, 597-611.

Potter, S., 2007. Fine-tuning Fujita. Weatherwise 60 (2), 64-71.

Powell, M.D., Reinhold, T.A., 2007a. Tropical cyclone destructive potential by integrated kinetic energy. Bull. Am. Meteor. Soc. 88 (4), 513-526.

Powell, M.D., Reinhold, T.A., 2007b. Reply. Bull. Am. Meteor. Soc. 88 (11), 1800-1801.

Powell, M.D., Reinhold, T.A., 2008a. Reply. Bull. Amr. Meteor. Soc. 89 (2), 221-223.

Powell, M.D., Reinhold, T.A., 2008b. Reply. Bull. Amr. Meteor. Soc. 89 (10), 1577.

Renno, N.O., 2008. A thermodynamically general theory for convective vortices. Tellus 60A, 688-699.

Rossmann, F., 1959. Über Baumzerstörung durch Tromben, besonders durch Verdrehen der Bäume (On tree destruction by tornadoes, especially by torsion of tree trunks). Meteor. Rundsch. 12 (5), 161-162 (In German).

Schielicke, L., Névir, P., 2009. On the theory of intensity distributions of tornadoes and other low pressure systems. Atmos. Res. 93, 11-20 (this issue).

Simpson, R.H., 1974. The hurricane potential-damage scale. Weatherwise 27, 169-186.

Simpson, R., Saffir, H., 2007. Comment on "Tropical cyclone destructive potential by integrated kinetic energy". Bull. Am. Meteor. Soc. 88 (11), 1799-1800.

Webster, P.J., Holland, G.J., Curry, J.A., Chang, H.R., 2005. Changes in tropical cyclone number, duration, and intensity in a warming environment. Science 309, 1844-1846. doi:10.1126/science.1116448.

Wegener, A., 1917. Wind- und Wasserhosen in Europa (Tornadoes in Europe). Verlag Friedrich Vieweg und Sohn, Braunschweig. 301 pp. [In German, available at essl.org].

WMO (Eds.), 1975: Technical regulations - WMO-Nr. 49, Appendix H. Geneva.

WSEC (Ed.), 2004. A recommendation for an enhanced Fujita scale (EFscale). Wind Science and Engineering Center, Texas Tech University, Lubbock, Texas. 95 pp. [Available at www.wind.ttu.edu/F_scale/images/ efsr.pdf and www.spc.noaa.gov/faq/tornado/ef-ttu.pdf].

Wurman, J., Alexander, C.R., 2005. The 30 May 1998 Spencer, South Dakota, storm. Part II: comparison of observed damage and radar-derived winds in the tornadoes. Mon. Weather Rev. 133, 97-119.

Wurman, J., Alexander, C., Robinson, P., Richardson, Y., 2007. Low-level winds in tornadoes and potential catastrophic tornado impacts in urban areas. Bull. Am. Meteor. Soc. 88 (1), 31-46. 